\title{
Simulations of Hadoop/MapReduce-Based Platform to Support its Usability of Big Data Analytics in Healthcare
}

\author{
By Dillon Chrimes* \\ Hamid Zamani ${ }^{\dagger}$ \\ Belaid Moa \\ Alex Kuo"
}

In many hospital systems, new technologies that influence patient data require extensive technical testing before implementation into production. Therefore, to implement, an existing High Performance Computing (HPC) Linux node clusters via WestGrid were used to represent a simulation of patient data benchmarked and cross-referenced with current metadata profiles in operational hospital systems at the Vancouver Island Health Authority (VIHA), Victoria, Canada. Over the tested cross-platform, the data were generated, indexed and stored over a Hadoop Distributed File System (HDFS) to noSQL database (HBase) that represented three billion patient records. The study objective to establish an interactive Big Data Platform (BDA) was successful implemented in that Hadoop/MapReduce technologies formed the framework of the platform distributed with HBase (key-value NoSQL database storage) and generated desired hospital-specific metadata at very extremely large volumes. In fact, the framework over generated HBase data files took a week or a month for one billion (10TB) and three billion (30TB), respectively. Further performance tests retrieved results from simulated patient records with Apache tools in Hadoop's ecosystem. At optimized iteration, HDFS ingestion with HBase exhibited sustained database integrity over hundreds of iterations; however, to complete the bulk loading via MapReduce to HBase required a month. Inconsistencies of MapReduce limited the capacity to generate/replicate data to HBase efficiently. Hospital system based on patient encounter database was very difficult and data profiles were fully representative of complex patient-to-hospital relationships. Our platform is important to lead discovery of useful big data technologies across multiple hospital systems.

Keywords: Analytics, Big Data, Cross Platform, Distributed Data, Distributed Filing System, Healthcare, High Performance Computing, Hospital System, Interactive Query, Relational Database.

\section{Introduction}

Big Data is a collection of data that is large, complex, distributed, and growing fast (or 5Vs- volume, variety, velocity, veracity, and value) (Hansen et al., 2014; Manyika et al., 2013). It has high potential for unlocking new sources of economic values, providing fresh insights into medical sciences and industrial

\footnotetext{
*Technical Integration Coordinator, Vancouver Island Health Authority, Canada.

${ }^{\dagger}$ School of Health Information Science, University of Victoria, Canada.

"Compute Canada/WestGrid/University Systems, University of Victoria, Canada.

'School of Health Information Science, University of Victoria, Canada.
} 
systems while assisting on policy making and reducing costs (Canada Health Infoway, 2013; Dufrense et al., 2014). Several published studies have asserted that Big Data managed efficiently can improve care delivery while reducing healthcare costs (Canada Health Infoway, 2013; Hansen et al., 2014; Manyika et al., 2013; Raghupathi and Raghupathi, 2014). A McKinsey Global Institute study suggests, "If US healthcare were to use big data creatively and effectively to drive efficiency and quality, the sector could create more than $\$ 300$ billion in value every year" (Manyika et al., 2013). A number of published articles also reported using Big Data to improve population health with better policy decision making. For example, Dugas et al. (2012) collected 21 months (2009 Jan - 2010 Oct) of data at an urban academic hospital in Baltimore, Maryland US to assess the correlation of city Google Flu Trends (GFT) using big data technologies to find data trends over thousands of searched influenza cases. The study found that GFT had high correlation with the number of identified influenza results. Similarly, in 2010, during a major Haitian cholera outbreak, daily reported case data for all departments from the Haiti Ministry of Health and daily volume of Twitter posts containing the word "cholera" has similar large analytical patterns. The Twitter data (via Apache Storm - a big data technology) provided earlier disease outbreak information (Chunara et al., 2012). Similarly, in a study by Twist et al. (2016) a platform Constellation (using Apache Storm and Hadoop in real-time) was successfully deployed at the Children's Mercy Hospital $(\mathrm{CMH})$ in Kansas City (Missouri, US) to match patients' clinical data to their genome sequencing, thereby facilitating treatments (Twist et al., 2016) and faster time for analytical results from 50 to 26 hours (Miller et al., 2015; Saunders et al., 2012). Moreover, Big Data in healthcare includes nationally standardized data collection schema, internationally accepted medical classification and terminology (e.g. ICD, SNOMED CT), semi-structured data for data transportation (e.g. HL7 messages), unstructured clinical notes (physicians' progress notes, medical images (e.g. MRI, X-rays), genetic lab data, and other types of data (e.g. public health and mental or behavioral health). Huge volumes of very heterogeneous raw data are generated daily by a variety of hospital systems (Kuo et al., 2014), such as Electronic Health Records (EHR), Computerized Physician Order Entry (CPOE), Picture Archiving and Communication Systems (PACS), Clinical Decision Support Systems (CDSS), and Provincial Laboratory Information Systems (PLIS).

In this study, we described our practical application among collaborations with Vancouver Island Health Authority (VIHA) funded research project "Design and Implement a Big Data Analytics Framework for Health Applications." The main objective of this project was to collaborate with the VIHA staff to develop and establish a BDA platform for application that applies to large sets of data collected from discharged patient records. A Hadoop/MapReduce framework formed the platform with noSQL database called HBase representing real hospital-specific metadata and file ingestion. The modeled data produced through technological framework and processes, formed three billion of emulated patient data. This data were generated and cross-referenced with inpatient 
profiles based on the metadata dictionaries provided through consultation and meeting with the VIHA's staff.

\section{Literature Review}

Big Data Analytics (BDA) designed and engineered in many industrial systems is developed to extract knowledge via data mining processes from sets of Big Data (Baro et al., 2015). Wang et al. (2014) further described the extraction of useful knowledge from Big Data in terms of a processing pipeline that transfers, stores, and analyses data for whole systems. According to Chrimes et al. (2017a) the review of processes of achieving full Big Data utilization involves five distinct configuration stages; each with specific challenges, as follows:

1. Data aggregation: Copy/transfer data to a storage drive is a commonly used method of aggregating and migrating large quantities of data (Kuo et al., 2014). Big Data research projects usually involve multiple organizations, geographic locations, and research IT teams; therefore, generating large datasets from replication away from production systems at hospitals removes any ongoing network resource consumption and database resources that could render the system in operable. Further, exchange of data between groups and databases is very difficult to coordinate; hence, a second database for big data should be carried out to ease its maintenance and slightly separate operational issues. Furthermore, transferring vast amounts of data over the network requires a significant amount of bandwidth over a consistent long duration. Additionally, to replicate data from the sources and generate it iteratively across instances and multiple nodes, as Hadoop Distributed File System (HDFS) can accomplish, does require batch processes or file block process (Grover et al., 2015; Lai et al., 2014; White, 2015).

2. Data maintenance: Since Big Data involves large volumes; it is very difficult to maintain access to all the data for ongoing queries. Moreover, time and cost can prohibit small organizations and technical system development and integration departments from managing large amounts of data. Another challenge, in healthcare, is that real patient data, metadata, and data profiles need to constantly be updated with clinical events table; otherwise, the analytics is rendered useless. There are many solutions available to provide maintenance including cloud computing (Dai et al., 2012) grid computing (Mohammed et al., 2014), NoSQL/NewSQL and other storage systems (e.g., MongoDB, HBase, Voldemort DB, Cassandra, Hadoop Distributed File System (HDFS) and Google's BigTable (Lith and Mattson, 2010; Moniruzzaman and Hossain, 2013).

Legality and ethics is also a major issue in data maintenance. Security, confidentiality and privacy are all mandated by Canadian legislation with strict regulations for Canada's public healthcare. Furthermore, Dufrense et al. (2014) point out that Canadians have a nationalistic view of their healthcare system, and public disclosure of data in a publicly provided healthcare system makes sense to many citizens, including providers and health professionals. For example, the Health Insurance Portability and Accountability Act (HIPPA) require the 
removal of 18 types of identifiers, including any residual information that could identify patients. Privacy concerns can be addressed using new technologies, such as key-value storage services, but advanced configuration and technical knowledge is needed. For example, Pattuk et al. (2013) proposed a framework for secure Big Data management involving an HBase database called Big Secret, which securely outsources and processes encrypted data over public key-value stores. Although hospitals house their data in server racks in a highly secure buildings and the vendors commonly are not allowed to use cloud services, especially when there is no control of the location.

3. Data integration: Data integration and interoperability processes involve combining and transforming data into an appropriate format for analysis. Since Big Data in healthcare are extremely large, distributed at different locations, unstructured and heterogeneous, the management of data integration over time is very time consuming (Dai et al., 2012; Martin-Sanchez and Verspoor, 2014). Numerous solutions have been proposed for raw Big Data integration (Chen et al., 2012b; Raghupathi and Raghupathi, 2014). The problem with these methods is they are problem-oriented, i.e., the method is only applied to specific data sets or aggregates. Very few generic approaches exist across integrated unstructured data.

4. Data analysis: Data analysis or analytics is highly important for a successful BDA (Chrimes et al., 2017b). BDA complexity involves analytic algorithms to be programmed in that the computing time increases dramatically even with small increases in data volume. However, it is very difficult to efficiently analyze the data interactively using traditional analytical software, such as IBM SPSS, Microsoft Excel or MathWorks MATLAB because Big Data is too large, too heterogeneous and highly distributed over many locations in the healthcare continuum. It can take several days, and most likely months, to obtain a result over a very large data set (in terabytes and beyond). Moreover, for complex analyses, the computing time increases exponentially even with incremental growth in the data size. For example, Bayesian Network are a popular algorithm for modeling knowledge in computational biology and bioinformatics, and the computing time required to find the best network increases exponentially, as the number of records rises (Schadt et al., 2010). Even for simple data analysis, it can take several days; even months, to obtain a result when databases are very large and SQL-like "joins" are executed.

Many studies suggest parallelization of computing model for high performance over analytical platforms to reduce computationally intense problems (Deepthi and Anuradha, 2016; Marozzo et al., 2012; Mohammed et al., 2014; Taylor, 2010; Vaidya and Deshpande, 2015; Wu et al., 2014; Zhang et al., 2015). In addition, using the traditional analysis methods, the error rate related to analyzing large amount of data may add a new dimension to the challenge of analyzing large data sets. Whereas, in BDA, the large sets are frequently analyzed without any mention of the error dimension. To address the analytical challenges, many recently published studies have suggested that using High Performance Computing (HPC), and parallelization of computing model can efficiently increase analysis performance for the computationally intense problems 
(Deepthi and Anuradha, 2016; Mohammed et al., 2014; Vaidya and Deshpande, 2015; Wu et al., 2014; Zhang et al., 2015).

5. Pattern interpretation: Knowledge representation is an absolute must to achieve for any data mining over BDA platforms. Further, BDA is of little value if decision-makers do not understand the patterns. Additionally, given the complex nature of the data and how big data technologies can increase users' interactive queries and utilization, representations of trends and individualized results will not be comprehensible to non-experts. Moreover, many people instinctively believe that bigger data means better information. But agile data science cannot protect us from inaccuracies and faulty assumptions. Many reporters are often fooled into thinking that correlations have true significance (or lack thereof).

\section{Methodology}

The basic premise of a BDA platform in healthcare was to construct the platform capable of compiling large heterogeneous clinical data from diverse sources while querying large volumes quickly and efficiently. We must create a simulated technical and operational environment with the cross platform over billions of patient records under performance of valuable data queries. Furthermore, it needs to be proven possible that it is beneficial to implement as a bolt-on solution to the current hospital system. Also, the applications were required to ensure patient data security and privacy with legislation, confidentiality laws and regulations. It must cover the complex relationships in the clinical event table of a patient in the hospital system with possible multi-encounters that are interrelated, for example chronic severe mental health, diabetes, and substance abuse as shown in Figure 1. As well as movement of patients in the hospital with medical services and health outcomes must be incorporated in the data schema to query interactively.

Figure 1. A Patient (at Start) Showing Multiple Encounters and Complex Relationships in the Patient Record of the Hospital System (with an End Point)

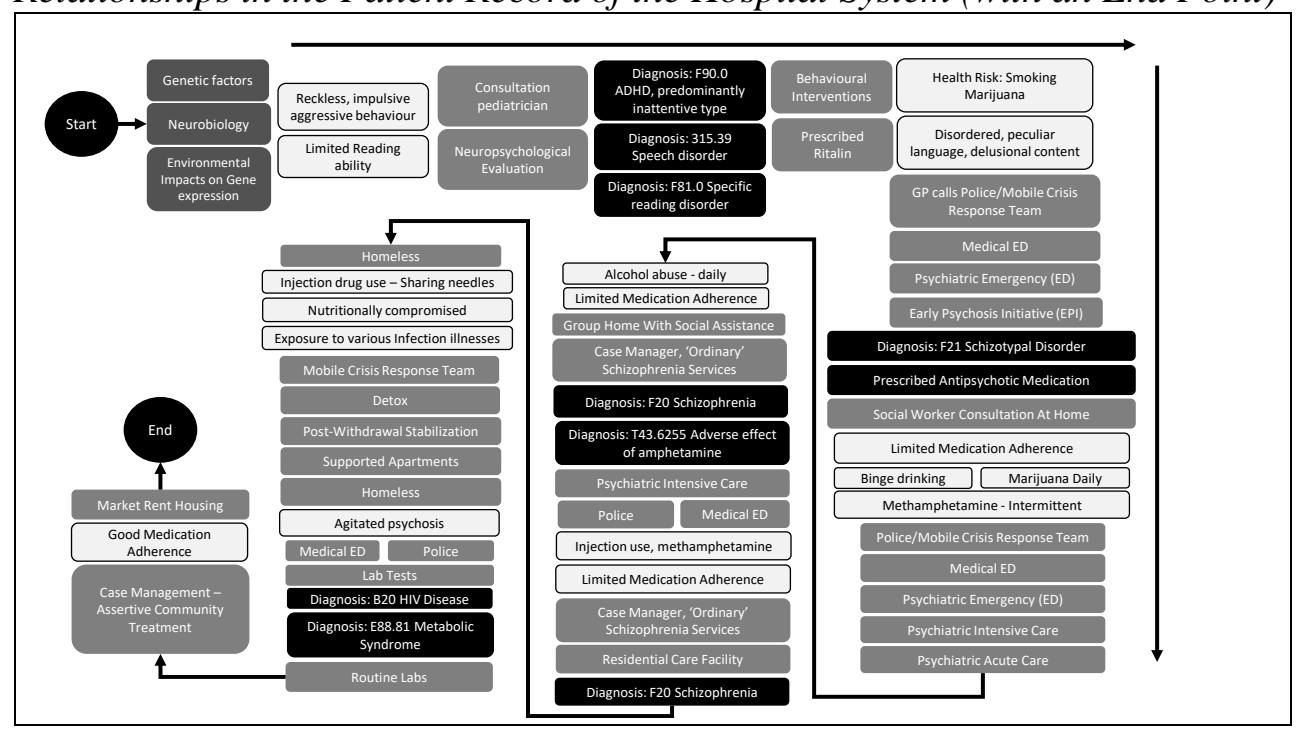




\section{Platform Architecture}

The BDA platform harnesses the technical power and advanced programming to produce accessible front-end tools to end users that allow for analysis of large quantities of back-end data in an interactive enriching manner. All this must be accomplished cost effectively under rigorous and varied usability user acceptance tests (UATs) to be deployed to production. Based on the design philosophy of simulation with multiple interactive components for end users to query data at extreme volumes within seconds, we constructed a dynamic platform with interfaced backend applications, such as Apache Phoenix, Spark, and Drill, linked to backend HBase over Hadoop Distributed File System (HDFS). With the Hadoop/MapReduce framework, the platform allowed users to easily analyze and visualize health Big Data (Chrimes et al., 2017b). The overall platform included four main components (shown in Figure 2):

\section{Figure 2. Big Data Analytics Platform Architecture}

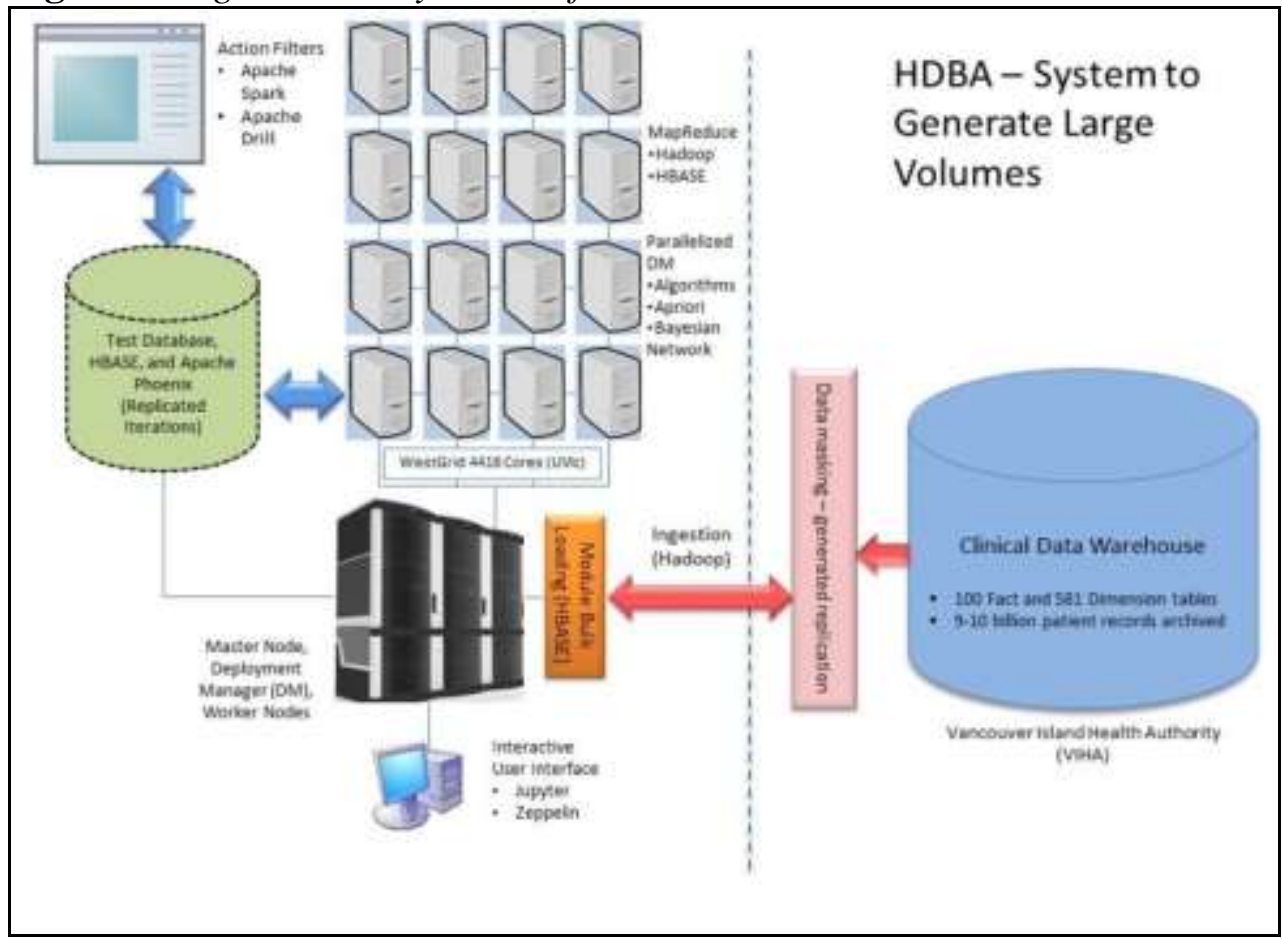

1. A clinical data warehouse stores healthcare data. Currently at VIHA there are over 1000 tables in its Admission, Discharge and Transfer (ADT) data from hospital system, and annually ca. one million patient encounters add to 50+ years archive (500 million at VIHA and 10 billion provincially).

2. High performance Linux clusters (WestGrid University System) were used to install software, build configurations, and run simulation queries (Hadoop ecosystem, Apache Phoenix, Spark and Drill).

3. HBase no SQL database was used to store data from VIHA clinical data warehouse. HDFS distributes the data to indexed storage across the WestGrid clusters with backup, high availability and redundancy. 
4. A master deployment manager (DM) was used to access the clusters from sponsored accounts over the Portable Batch System (PBS) of the Resource Manager (RM). The access to the DM is controlled by lightweight directory access protocol (LDAP) while accessing worker nodes was restricted to only the user running the job. This architecture permitted an agile and stabilized access with system administrator that could be launched from any terminal for each PBS job.

\section{High Performance Computing (HPC) Infrastructure}

In this study, as described above, we relied on WestGrid's existing architecture as the computing infrastructure. WestGrid is a nationally Canadian funded program since 2003, mainly used in western Canada while EastGrid and Ontario and Quebec grids are available. WestGrid installation at the University of Victoria (UVic) started in July 2010. The WestGrid computing facilities at UVic have 2 main clusters called Hermes and Nestor. Hermes is a capacity cluster geared towards serial jobs with 84 nodes having 8 cores each and 120 nodes with 12 cores each, which gives a total of 2112 cores. Nestor is a large cluster consisting of 288 nodes (2304 cores) geared towards large parallel jobs. The computing system of these two clusters share infrastructure such as resource management, job scheduling, networked storage, and service and interactive nodes. In this study, we use five dedicated worker nodes and one head node from Hermes cluster.

\section{Conceptual Analytics Framework}

Under the umbrella of the hospital system and its end users, the framework and the applications would allow users to query, visualize, interpret, and modify outputs of the data. The overall purpose was to make Big Data capabilities accessible to stakeholders, including UVic researchers, VIHA physicians and database administrators, and other healthcare practitioners. Our analytics framework on the platform includes nine technical integrated parts of the system:

1. A clinical data warehouse was part of the main goal to achieve billions of patient records to represent Big Data in healthcare application. Currently, the data warehouse at VIHA has over 1000 relational tables of its hospital system that encompass ten billion records archived over a period of $\sim 50$ years. Health data are continuously generated and added to the warehouse at a rate which has grown exponentially to over one million encounters annually at VIHA.

2. A back-end NoSQL database of HBase with indexing rows to columns uniquely and key-stores that encrypts the data. In the emulation of the database, each row represented encounter-based patient data as a Big Integer, with diagnoses, interventions, and procedures specific to that patient, which the current ADT system has in its database schema linked to a bigger data warehouse, which includes DAD (Table 1). This patient- 
specific structure in the database allowed for active updates to add to the data generation while maintaining accurate patient querying over the platform. Patient-specific rows across the columns according to the existing abstraction were essential part of the emulation; HBase established a wide range of indexes for each unique row, and each row contained a key value that was linked to the family of qualifiers and primary keys (columns). HBase was chosen due to its NoSQL services, especially linear to modular scalability to document architecture. In addition, it allows for SQL-like layer of Apache Phoenix to be configured on top of HBase bigtables. The HBase operations were specific to family qualifiers at each iteration; therefore, the data was patient-centric combined with certain DAD data (from different sources of metadata) in the rows and columns, such that summary of diagnosis or medical services as a whole could be queried. The BDA platform was built on top of the available open-source software (HBase). HBase (NoSQL version 0.98.11) is a NoSQL database composed of the main deployment master (DM) node and its fail-over master, the Region Servers holding HBASE data, and ZooKeeper, which contained services to allocate data locality (Zookeeper, 2016), of three nodes, that orchestrated that ensemble. The xml configuration files were HBase-site.xml and the HBase-env.sh were adjusted to improve the performance of HBase.

Table 1. Data Schema of Patient Data CREATE TABLE IF NOT EXISTS DADS1 (

EncounterID BIGINT NOT NULL,

Admit_by_Ambulance VARCHAR,

Admit_Category VARCHAR,

Admission_Date VARCHAR,

Admission_Time VARCHAR,

Age INTEGER,

Anesthestic_Grade VARCHAR,

Anesthetist_ID VARCHAR,

Anesthetistic_Technique INTEGER,

Arrival_Date_in_ER VARCHAR NOT NULL,

Arrival_Time_in_ER VARCHAR NOT NULL,

Date_Patient_Left_ED VARCHAR,

Date_of_Transfer_In VARCHAR,

Days_in_Unit VARCHAR,

Discharge_Date VARCHAR NOT NULL,

Discharge_Disposition VARCHAR NOT NULL,

Discharge_Site VARCHAR NOT NULL,

Discharge_Time VARCHAR NOT NULL,

Birth_Date VARCHAR,

Diagnosis_Cluster VARCHAR,

Diagnosis_Code VARCHAR NOT NULL,

Diagnosis_Occurrence INTEGER,

Diagnosis_Prefix VARCHAR,

Diagnosis_Type VARCHAR,

Entry_Code VARCHAR, 


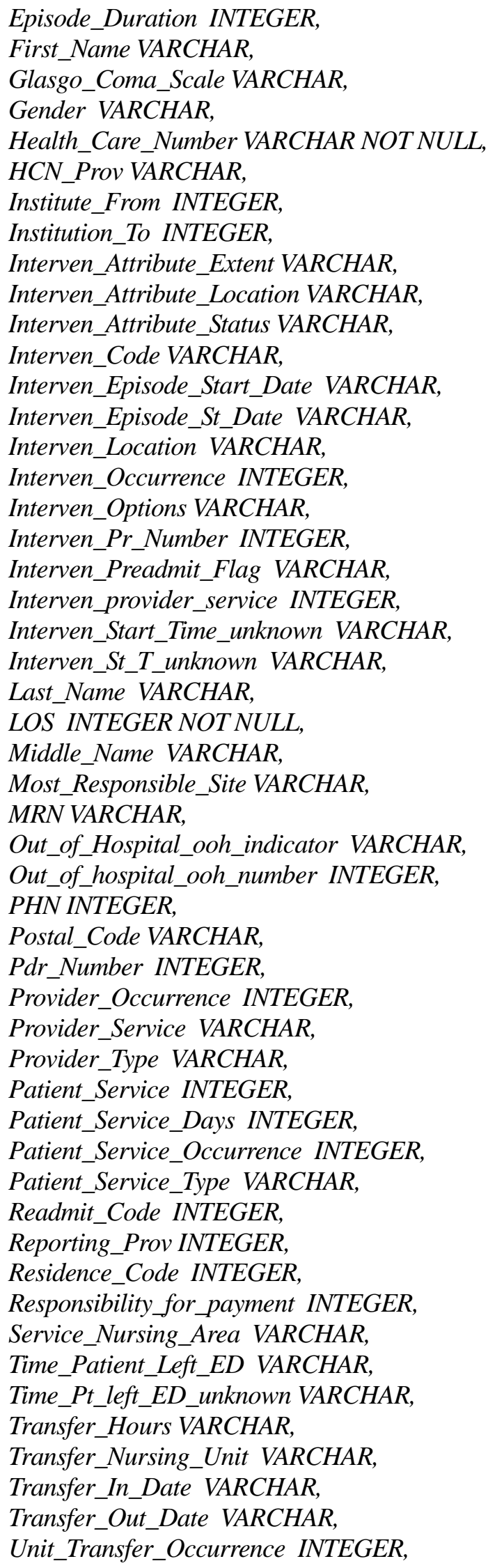


Unplanned_return_to_OR VARCHAR,

Wait_Time_in_ED VARCHAR,

FIN INTEGER NOT NULL,

Encounter_Number INTEGER NOT NULL,

Admit_Source VARCHAR,

Encounter_Type VARCHAR,

Medical_Services VARCHAR,

MostResponProvider VARCHAR,

Address VARCHAR,

Family_Physician VARCHAR,

Location_Building VARCHAR NOT NULL,

Location_unit VARCHAR NOT NULL,

Location_Room VARCHAR NOT NULL,

Location_Bed VARCHAR NOT NULL,

CONSTRAINT PK PRIMARY KEY (EncounterID, Arrival_Date_in_ER,

Arrival_Time_in_ER, Discharge_Date, Discharge_Disposition, Discharge_Site,

Discharge_Time, Diagnosis_Code, Health_Care_Number, OS, FIN,

Encounter_Number, Location_unit), Salt Buckets $=5$.

3. The construction and build of the framework of HBase (NoSQL) across Hadoop (HDFS) with MapReduce components established the BDA platform. This construct coincided with and was enforced by the existing architecture of the WestGrid clusters at UVic(secure login via LDAP directory to deployment database nodes and restricted accounts to dedicated nodes). It was initially running the architecture of the platform with five worker nodes and one master node (each with 12 cores). The data were distributed in parallel on the nodes via a balanced allocation to each local disk with running part of the batch jobs with set metadata and columns for each row up to 50 million in a serial computing process that generated replications.

4. A HPC clusters with a total of 4412 cores with batch processing and parallelized nodes. Hermes has 2112-core capacity cluster(s) geared towards serial jobs that can be distributed. It consists of 84 nodes having eight cores each and 120 nodes with 12 cores each. The systems are designed for high-performance and advanced-research computing and include clusters with fast interconnection and shared memory systems. Serial programs run on one CPU or core on a computing cluster node. Parallel programs, on the other hand, may have multiple processes or threads running at the same time, so that installations need to communicate to carry out their tasks. This study used both types to send job to ingest file and also to run the Hadoop/MapReduce framework or parallel program process. It also utilized the batch serial process to access and start jobs over the Hadoop top-down head node to slave architecture.

5. A master DM is the portable batch serial login that was configured as head node to worker nodes. Deployment of the Hadoop environment on the nodes carried out via a sequence of setup scripts that the user calls after loading the modules and setup additional configuration to the head node with YARN and ZooKeeper as allocators of various deployments. Setup 
scripts created an initial configuration depending on the number of nodes chosen when launching the job. The user can adjust those configurations to match the needs of the job and its performance.

6. Making the BDA platform InfiniBand-enabled was challenging, as most of the Hadoop environment services rely on the hostname to get the IP address of the machine. Since the hostnames on a cluster are usually assigned to their management network, the setup scripts and the configuration files required adjustment. The InfiniBand was used because it offers low latency (in us) and high bandwidth $(\sim 40 \mathrm{~Gb} / \mathrm{s})$ connectivity between the nodes. YARN, Hadoop's resource and job manager, unfortunately still partly used the Gig-Ethernet interface when orchestrating between the nodes, but the data transfer was carried out on the InfiniBand. Yarn was the resource manager of Hadoop and services of scheduling incongruent to running the Hadoop jobs. In addition to the MapReduce component, Yarn and HDFS constitute the main components (Taylor, 2010).

7. The queries via Apache Phoenix (version 4.3.0) resided as a thin SQL-like layer on HBase. This allowed ingested data to form structured schemabased data in the NoSQL database. Phoenix can run SQL-like queries against the HBase data. Similar to the HBase shell, Phoenix is equipped with a python interface to run SQL statements and it utilizes a .csv file bulk loader tool to ingest a large flat file using MapReduce. The load balancing between the RegionServers (e.g. "salt bucket") was set to the number of slaves or worker nodes that allowed ingested data to be balanced and distributed evenly.

8. Apache Spark was also built from source and installed to use on HBase and the Hadoop cluster. Spark utilizes Yarn and HDFS architecture and is known to scale and perform well in the data space (over distributed files over multiple nodes).

9. Inspired by Google's big query engine Dremel, Drill supports a wide range of data sources, including .csv, JSON, HBase, etc. (Sitto and Presser, 2015). By (re)compiling and optimizing each of the queries while it interacts with the distributed data sets via the so-called drillbit service, Drill showed capacity of the query with performance at a low latency SQL query.

\section{Developing Tools}

Several of the open-source software were installed and configured to form the analytics platform (Chrimes et al., 2017b). The software stack formed is shown in Figure 3. 
Figure 3. Software Stack

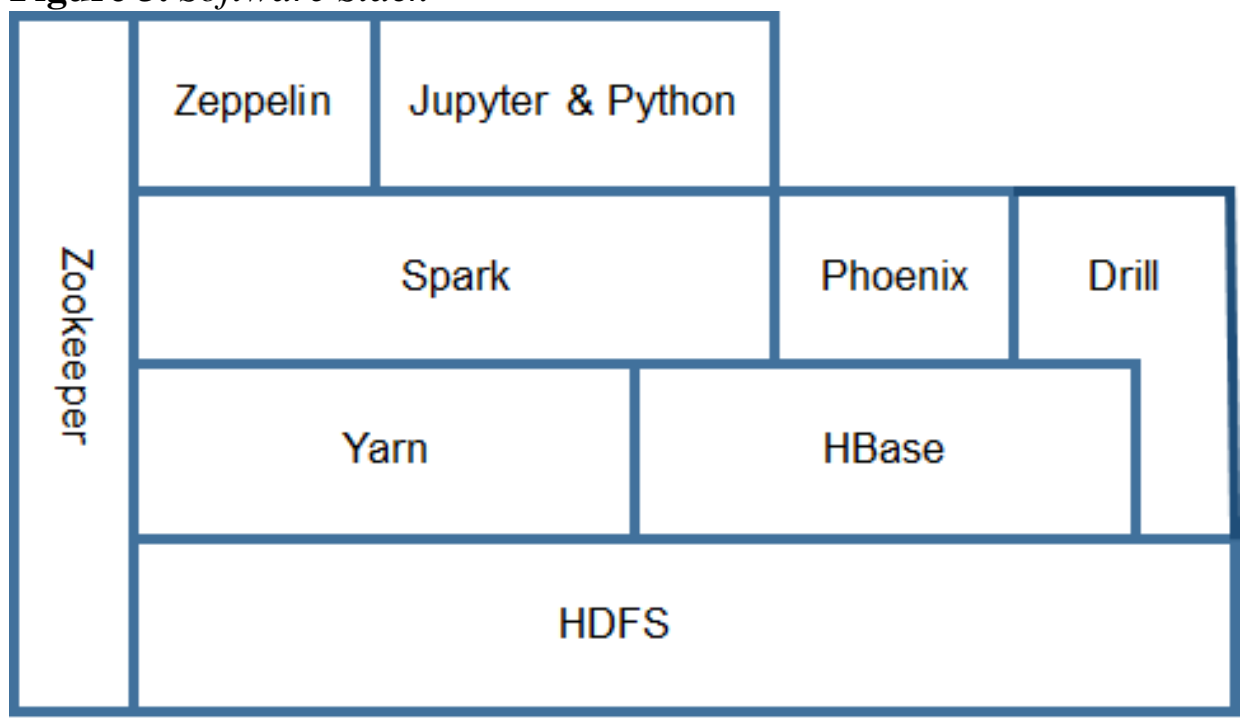

Apache Zeppelin 0.6.0 is a web-based notebook that enables interactive data analytics via local host and Spark-SQL. Ithas many built-invisualization features to support knowledge presentation. Similarly, Jupyter 4.0.6 (formerly known as iPython Notebook) is an interactive notebook that supports users to interact with data in various programming languages and combine code with markdown text to perform visualizations.

Apache Spark (1.3.0 to 1.5.2) is an open-source parallel processing framework to utilize Yarn (Hadoop's resource manager) and less use of MapReduce for running large-scale data analytics applications across computer clusters. It has its own SQL-like queries built in. Apache Phoenix 4.3.0 is an open-source skin on HBase that provides a Java Database Connectivity (JDBC) driver and SQL-like access. Phoenix enables Online transaction Processing (OLTP) and operational analytics over Hadoop's foundation for low latency applications. It compiles SQL-like query into a series of HBase scans, and it orchestrates the running of those scans to produce regular JDBC result sets. Phoenix is fully integrated with other Hadoop products such as Spark, Hive, Pig, Flume, and MapReduce.

Drill 1.3.0 is also Apache open-source software (established 2015) that supports data-intensive distributed large-scale datasets using SQL ANSI: 2003 query types. It offers a low latency query engine and utilizes Zoo Keeper. As opposed to the master/slave architecture of Spark in which a driver is handling the execution of the Directed Acyclic Graph (DAG) on a given set of executors, the drillbits are loosely coupled and each can accept a query from the client (Chrimes et al., 2017b). To run Drill over a distributed mode, the user will need a ZooKeeper cluster continuously running. Drill 1.3.0 and ZooKeeper 3.4.6 were installed and configured on the framework of the platform over a port with a local host. The receiving drillbit becomes the driver for the query, parsing, and optimization over a generated efficient, distributed, and multiphase execution 
plan; it also gathers the results back when the scheduled execution is done (Dunning et al., 2016; Jurney, 2013).

At the foundation of the stack is HDFS. It is the most important foundational component of the platform. Yarn is there source manager of Hadoop and services of scheduling incongruently running the jobs. In addition to Map Reduce component, Yarn and HDFS constitute the main components of Hadoop 2.6.0 version.

\section{Data Privacy Protection}

Ensuring patient data security and privacy was an important requirement in this study. The established platform used the three following methods to protect data security and privacy:

Data Masking - Typically this is carried out by database administrators thru rules and regulations set by business/security analysts based on current legislations of BC Ministry of Health. The goal was to generate a comprehensive list of sensitive elements specific to the organization and associated tables, columns, and relationships across the data warehouse and encryption of indexed key stores provided by HBase(Chrimes et al., 2017a).

Data replication - We worked in conjunction with Business Intelligence and Data warehouse, Clinical reporting, Application Platform Services, Database Administrators, and Physicians/Nurses groups to identify the masking or encryption required and optimal techniques to de-identify and restrict access to patient data. Once the data form distributed HBase data sets across working nodes, it was queried via Apache Phoenix, Spark and Drill only thru PBS held by WestGrid.

Using HBase over Security/Privacy Mechanisms - HBase provided comprehensive security/privacy support thru its qualifiers and key-stores of data ingested. The access control to data stored in HBase was at table level, column family level and column level. HBase supports Kerberos authentication, Remote Procedure Call (RPC) and at-rest privacy protection. Data could not be queried without WestGrid for authentication.

\section{Findings/Results}

\section{Data Emulation and Modeling}

Over the span of twelve months in 2014-2015, several interviews were conducted with business intelligence data warehouse, clinical reporting, application platform, and health informatics architecture teams employed at VIHA (Table 2). During these interviews, an emulated health Big Data was generated from hospital admissions (based on encounter types) and a discharge system (based on diagnoses and procedures). In it, data profiles (including dependencies) and the importance of the metadata for the clinical reporting were confirmed and verified. Furthermore, current reporting limitations of the different combinations 
of the DAD and ADT data were recorded to form accurate simulation of the existing and future queries (Wu et al., 2014). To test the feasibility of the BDA platform and its performance, the emulated patient data had 90 columns that combined DAD and ADT metadata profiles.

Table 2. Use Cases and Patient Encounter Scenarios related to Metadata of the Patient Visit and its Placement in the Database related to Query Output

\begin{tabular}{|c|c|c|c|c|}
\hline $\begin{aligned} \text { Case } \\
\text { No. } \\
\end{aligned}$ & $\begin{array}{l}\text { Case } \\
\text { Description } \\
\end{array}$ & $\begin{array}{l}\text { Column (Metadata) Used } \\
\text { for Analysis }\end{array}$ & $\begin{array}{l}\text { Database } \\
\text { Build }\end{array}$ & Query Output \\
\hline 1 & $\begin{array}{l}\text { Uncontrolled } \\
\text { Type } 2 \text { diabetes } \\
\text { \& Complex } \\
\text { comorbidities }\end{array}$ & $\begin{array}{l}\text { ICD10-CA, MRN, PHN } \\
\text { and LOS, Discharge }\end{array}$ & $\begin{array}{l}\text { DAD with } \\
\text { Diagnosis } \\
\text { Codes, patient } \\
\text { IDs and } \\
\text { Discharge in } \\
\text { Columns }\end{array}$ & $\begin{array}{l}\text { ICD10-CA codes with } \\
\text { counts, frequencies or } \\
\text { max values for patient } \\
\text { encounters }\end{array}$ \\
\hline 2 & $\begin{array}{l}\text { TB of the lung } \\
\& \text { uncontrolled } \\
\text { DM } 2\end{array}$ & $\begin{array}{l}\text { ICD10-CA, MRN, PHN, } \\
\text { Inpatient Encounter, } \\
\text { Location, Unit Transfer }\end{array}$ & $\begin{array}{l}\text { DAD and ADT } \\
\text { columns }\end{array}$ & $\begin{array}{l}\text { ICD10-CA and } \\
\text { encounter type codes } \\
\text { with counts, } \\
\text { frequencies or max } \\
\text { values for patient } \\
\text { encounters }\end{array}$ \\
\hline 3 & $\begin{array}{l}\text { A on C Renal } \\
\text { Failure, } \\
\text { Fracture, Heart } \\
\text { Failure to CCU } \\
\text { and stable DM } 2\end{array}$ & $\begin{array}{l}\text { ICD10-CA, MRN, PHN, } \\
\text { Intervention (CCI), } \\
\text { Episode, Unit Transfer, } \\
\text { Bed Location, CCU codes, } \\
\text { Discharge }\end{array}$ & $\begin{array}{l}\text { DAD and ADT } \\
\text { columns }\end{array}$ & $\begin{array}{l}\text { ICD10-CA, CCI and } \\
\text { encounter types and } \\
\text { unit transfer and bed } \\
\text { location codes with } \\
\text { counts, frequencies or } \\
\text { max values for patient } \\
\text { encounters }\end{array}$ \\
\hline 4 & $\begin{array}{l}\text { Multi-location } \\
\text { Cancer patient } \\
\text { on Palliative }\end{array}$ & $\begin{array}{l}\text { ICD10-CA, MRN, PHN, } \\
\text { Intervention (CCI), } \\
\text { Surgery, Episode, Bed } \\
\text { Location, Transfer to ALC } \\
\text { Unit, Medical Services and } \\
\text { Patient Services, Discharge }\end{array}$ & $\begin{array}{l}\text { DAD and ADT } \\
\text { columns }\end{array}$ & $\begin{array}{l}\text { ICD10-CA, CCI and } \\
\text { encounter types and } \\
\text { unit transfer and bed } \\
\text { location and medical } \\
\text { service codes with } \\
\text { counts, frequencies or } \\
\text { max values for patient } \\
\text { encounters }\end{array}$ \\
\hline 5 & $\begin{array}{l}1 \text { cardiac with } \\
\text { complications }\end{array}$ & $\begin{array}{l}\text { ICD10-CA, MRN, PHN, } \\
\text { Intervention (CCI), } \\
\text { Surgery, Episode, Bed } \\
\text { Location, Transfer, } \\
\text { Medical Services, } \\
\text { Discharge }\end{array}$ & $\begin{array}{l}\text { DAD and ADT } \\
\text { columns }\end{array}$ & $\begin{array}{l}\text { ICD10-CA, CCI and } \\
\text { encounter types and } \\
\text { transfer codes with } \\
\text { counts, frequencies or } \\
\text { max values for patient } \\
\text { encounters }\end{array}$ \\
\hline 6 & $\begin{array}{l}1 \text { ER to } \\
\text { surgical, } \\
\text { Fracture, re- } \\
\text { admit category } \\
7 \text { days and some } \\
\text { complication } \\
\text { after }\end{array}$ & $\begin{array}{l}\text { ICD10-CA, MRN, PHN, } \\
\text { Intervention (CCI), } \\
\text { Surgery, Episode, Bed } \\
\text { Location, Medical } \\
\text { Services, Progress Notes, } \\
\text { Discharge, Re-Admission }\end{array}$ & $\begin{array}{l}\text { DAD and ADT } \\
\text { columns }\end{array}$ & $\begin{array}{l}\text { ICD10-CA, CCI and } \\
\text { medical services and } \\
\text { re-admit codes with } \\
\text { counts, frequencies or } \\
\text { max values for patient } \\
\text { encounters }\end{array}$ \\
\hline 7 & $\begin{array}{l}1 \text { Simple Day- } \\
\text { Surg. with } \\
\text { complication, so } \\
\text { got admitted to } \\
\text { Inpatient } \\
\text { (Allergy to } \\
\text { medication) }\end{array}$ & $\begin{array}{l}\text { ICD10-CA, MRN, PHN, } \\
\text { Intervention (CCI), } \\
\text { Surgery, Bed Location, } \\
\text { Medical Services, } \\
\text { Discharge }\end{array}$ & $\begin{array}{l}\text { DAD and ADT } \\
\text { columns }\end{array}$ & $\begin{array}{l}\text { ICD10-CA, CCI and } \\
\text { medical services codes } \\
\text { with counts, } \\
\text { frequencies or max } \\
\text { values for patient } \\
\text { encounters }\end{array}$ \\
\hline 8 & $\begin{array}{l}1 \text { cardiac with } \\
\text { complications } \\
\text { and Death }\end{array}$ & $\begin{array}{l}\text { ICD10-CA, MRN, PHN, } \\
\text { Intervention (CCI), } \\
\text { Episode, Bed Location, }\end{array}$ & $\begin{array}{l}\text { DAD and ADT } \\
\text { columns }\end{array}$ & $\begin{array}{l}\text { ICD10-CA, CCI and } \\
\text { medical services, } \\
\text { discharge disposition }\end{array}$ \\
\hline
\end{tabular}




\begin{tabular}{|c|c|c|c|c|}
\hline & & $\begin{array}{l}\text { Transfer, Medical } \\
\text { Services, Discharge } \\
\text { Disposition }\end{array}$ & & $\begin{array}{l}\text { and transfer codes } \\
\text { with counts, } \\
\text { frequencies or max }\end{array}$ \\
\hline 9 & $\begin{array}{l}1 \text { Normal birth } \\
\text { with postpartum } \\
\text { hemorrhage } \\
\text { complication }\end{array}$ & $\begin{array}{l}\text { ICD10-CA, MRN, PHN, } \\
\text { Intervention (CCI), } \\
\text { Surgery, Episode, Bed } \\
\text { Location, Medical } \\
\text { Services, Discharge }\end{array}$ & $\begin{array}{l}\text { DAD and ADT } \\
\text { columns }\end{array}$ & $\begin{array}{l}\text { ICD10-CA, CCI and } \\
\text { medical services and } \\
\text { discharge codes with } \\
\text { counts, frequencies or } \\
\text { max values for patient } \\
\text { encounters }\end{array}$ \\
\hline 10 & $\begin{array}{l}1 \text { HIV/AIDS } \\
\text { patient treats for } \\
\text { underlying } \\
\text { factor (an } \\
\text { infection) }\end{array}$ & $\begin{array}{l}\text { ICD10-CA, MRN, PHN, } \\
\text { Medical Services, } \\
\text { Discharge }\end{array}$ & $\begin{array}{l}\text { DAD and ADT } \\
\text { columns }\end{array}$ & $\begin{array}{l}\text { ICD10-CA, and } \\
\text { medical services codes } \\
\text { with counts, } \\
\text { frequencies or max } \\
\text { values for patient } \\
\text { encounters }\end{array}$ \\
\hline 11 & $\begin{array}{l}\text { Strep A } \\
\text { infection }\end{array}$ & $\begin{array}{l}\text { ICD10-CA, MRN, PHN, } \\
\text { Medical Services, } \\
\text { Discharge }\end{array}$ & $\begin{array}{l}\text { DAD and ADT } \\
\text { columns }\end{array}$ & $\begin{array}{l}\text { ICD10-CA, and } \\
\text { medical services codes } \\
\text { with counts, } \\
\text { frequencies or max } \\
\text { values for patient } \\
\text { encounters }\end{array}$ \\
\hline 12 & $\begin{array}{l}\text { Cold but } \\
\text { Negative Strep } \\
\text { A. Child with } \\
\text { throat culture }\end{array}$ & $\begin{array}{l}\text { ICD10-CA, MRN, PHN, } \\
\text { Medical Services, } \\
\text { Discharge }\end{array}$ & $\begin{array}{l}\text { DAD and ADT } \\
\text { columns }\end{array}$ & $\begin{array}{l}\text { ICD10-CA, and } \\
\text { medical services codes } \\
\text { with counts, } \\
\text { frequencies or max } \\
\text { values for patient } \\
\text { encounters }\end{array}$ \\
\hline 13 & $\begin{array}{l}\text { Adult patient } \\
\text { with Strep A. } \\
\text { positive and } \\
\text { physical exam }\end{array}$ & $\begin{array}{l}\text { ICD10-CA, MRN, PHN, } \\
\text { Medical Services, Patient } \\
\text { Services, Discharge }\end{array}$ & $\begin{array}{l}\text { DAD and ADT } \\
\text { columns }\end{array}$ & $\begin{array}{l}\text { ICD10-CA, patient } \\
\text { and medical services } \\
\text { codes with counts, } \\
\text { frequencies or max } \\
\text { values for patient } \\
\text { encounters }\end{array}$ \\
\hline 14 & $\begin{array}{l}\text { Severe } \\
\text { Pharyngitis with } \\
\text { physical exam }\end{array}$ & $\begin{array}{l}\text { ICD10-CA, MRN, PHN, } \\
\text { Medical Services, Patient } \\
\text { Services, Discharge }\end{array}$ & $\begin{array}{l}\text { DAD and ADT } \\
\text { columns }\end{array}$ & $\begin{array}{l}\text { ICD10-CA, patient } \\
\text { and medical services } \\
\text { codes with counts, } \\
\text { frequencies or max } \\
\text { values for patient } \\
\text { encounters }\end{array}$ \\
\hline 15 & $\begin{array}{l}\text { Child, moderate } \\
\text { Pharyngitis, } \\
\text { throat culture } \\
\text { negative, } \\
\text { physical exam }\end{array}$ & $\begin{array}{l}\text { ICD10-CA, MRN, PHN, } \\
\text { Medical Services, } \\
\text { Discharge }\end{array}$ & $\begin{array}{l}\text { DAD and ADT } \\
\text { columns }\end{array}$ & $\begin{array}{l}\text { ICD10-CA, and } \\
\text { medical services codes } \\
\text { with counts, } \\
\text { frequencies or max } \\
\text { values for patient } \\
\text { encounters }\end{array}$ \\
\hline 16 & $\begin{array}{l}\text { Adult, history of } \\
\text { heart disease, } \\
\text { Positive culture } \\
\text { for Strep A. }\end{array}$ & $\begin{array}{l}\text { ICD10-CA, MRN, PHN, } \\
\text { Medical Services, Patient } \\
\text { Services, Discharge }\end{array}$ & $\begin{array}{l}\text { DAD and ADT } \\
\text { columns }\end{array}$ & $\begin{array}{l}\text { ICD10-CA, patient } \\
\text { and medical services } \\
\text { codes with counts, } \\
\text { frequencies or max } \\
\text { values for patient } \\
\text { encounters }\end{array}$ \\
\hline 17 & $\begin{array}{l}\text { Adult, physical } \\
\text { exam, moderate } \\
\text { pharyngitis, } \\
\text { positive for } \\
\text { strep A. culture } \\
\text { and positive } \\
\text { second time, re- } \\
\text { admit }\end{array}$ & $\begin{array}{l}\text { ICD10-CA, MRN, PHN, } \\
\text { Medical Services, Patient } \\
\text { Services, Discharge }\end{array}$ & $\begin{array}{l}\text { DAD and ADT } \\
\text { columns }\end{array}$ & $\begin{array}{l}\text { ICD10-CA, patient } \\
\text { and medical services } \\
\text { codes with counts, } \\
\text { frequencies or max } \\
\text { values for patient, } \\
\text { readmit encounters }\end{array}$ \\
\hline
\end{tabular}


We successfully benchmarked the performance of the BDA platform with clinical data warehouse utilization processes. Within the archive of data warehouse, two of the largest data sets are the Admission, Discharge, Transfer (ADT) and the Discharge Abstract Database (DAD). ADT has over 1000 tables with 75 columns containing individual patient bed-tracking information, while the DAD is set by a data dictionary (hundreds of data elements) of 28 columns contains Canadian Institute for Health Information's (CIHI) diagnostic codes and discharge abstract metadata. These data sets are not system linked to form an allencompassing database. In a hospital system, the capacity to record patient data efficiently in the ADT is crucial to timely patient care and quality patient-care deliverables. Thus, the ADT system is often referred to as the source of truth for reporting operations of inpatient to outpatient and discharged (Chrimes et al., 2017b). A suitable analysis of ADT and DAD integrated data in this study shows many benefits of using big data technologies to produce high volumes while interactively applying new ways to query the data to find unknown correlations and trends. Figure 4shows the overall industrial design of the platform crossover and bolt-on with the current production system.

Figure 4. Industrial Design of the Big Data Analytics (BDA) Platform as Bolt-on Solution to Hospital System Services Involving Physicians, Nurses, Health Professionals, Health Records, Data Warehouse, Database, Analytics and Application Platform Services Maintained with Patient Encounters into System

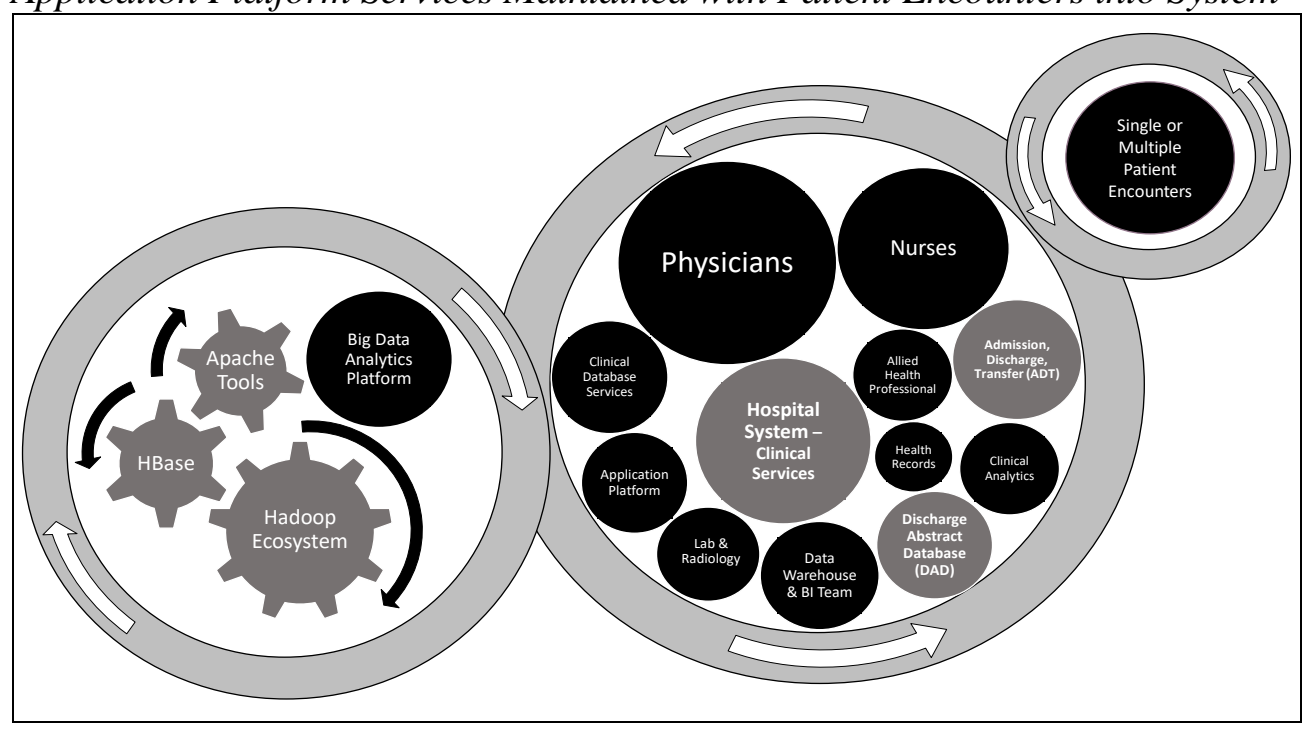

Data Ingestion and Query Performance

The pathway to running ingestions and queries over the BDA platform includes nine user-to-system steps (Chrimes et al., 2017b):

1. Generating . csv flat files

2. Apache Phoenix Module Load

3. HDFS Module and Ingestion of HFiles

4. BulkloadingHFiles to HBase 
5. HBase Compression

6. Phoenix SQL-like Queries

7. Apache Spark and Drill Module Loads

8. Notebook and Python/Pypark Module Loads

9. Spark and Drill SQL-like Queries

Thru this sequence, the Phoenix module loaded after Hadoop and HBase SQL code was directed and then iteratively run to ingest three billion rows to the existing HBase. Phoenix can run SQL-like queries against the HBase data. It was utilized to index and place schema over each .csv file bulk loaded to ingest using MapReduce. The queries via Apache Phoenix resided as a thin SQL-like layer on HBase. This allowed ingested data where the batch loads were 50 million each via the index and schema between HBase's Region Servers thru a functional SQL-like code of "salt bucket" that set the number of worker nodes in the cluster to five evenly distributed data. This additional code was deemed necessary as HDFS did not automatically distribute data evenly and queried unbalanced data showed slow performance. Performance was measured with three main processes: HDFS ingestions, bulk loads to HBase, and query times. Three flat files (.csv) with different number of rows (50 million, 1 and 3 billon) were ingested to HDFS for testing (Table 3).

Table 3. HDFS Data Ingestions

\begin{tabular}{|cc|}
\hline \hline Data Size & Ingestion Time \\
\hline 50 Million records (23GB) & $\sim 3-6 \mathrm{~min}$ \\
1 Billion records (451GB) & $\sim 60-120 \mathrm{~min}$ \\
3 Billion records (10TB) & $\sim 180-360 \mathrm{~min}$ \\
\hline \hline
\end{tabular}

At an optimized iteration, HDFS ingestion required three seconds but HBase required four to twelve hours to complete the Reducer of MapReduce. HBase bulk loads took a week for one billion and over two months for three billion (Table 4).

Table 4. HBase Distributed Data Durations

\begin{tabular}{|cc|}
\hline \hline Data Size & Completion Time \\
\hline 50 Million records (0.5TB) & $3-12 \mathrm{hrs}$ \\
1 Billion records (10TB) & $60-240 \mathrm{hrs}$ \\
3 Billion records (30TB) & $300-480 \mathrm{hrs}$ \\
\hline
\end{tabular}

A SQL script containing all the queries was written and ran using Phoenix sqline.py. The total number of queries that were used was 22: two simple queries with wildcard column selection; ten simple queries that did not involve more than three columns in the primary keys (family qualifiers); and, ten complex queries that had $>3$ columns selected (Table 5). All queries run on Zeppelin, Jupyter, Spark-terminal and Pyspark, as well as Drill took approximately the time of 50120 seconds to load the data and query. Spark was configured to run on specialized Yarn-client with 10 executors, four cores with 8 GB of RAM each; 
therefore, each node had two executors with a total of eight cores and 16 GB memory. However, Drill was faster with its configuration involving inherent ZooKeeper allocations via its drillbit components.

Table 5. Performance of Queries over 50 million (M), 1 and 3 Billion (B) Patient Records

\begin{tabular}{|c|c|c|c|}
\hline \multirow{2}{*}{ Query Questions } & \multicolumn{3}{|c|}{ Response Time (sec) } \\
\hline & 50M & 1B & 3B \\
\hline 1. Wildcard Selection of Encounter Data & 1.84 & 1.87 & 3.05 \\
\hline $\begin{array}{l}\text { 2. Wildcard Selection of EncounterID with } \\
\text { Ambulance Encounter }\end{array}$ & 1.83 & 1.77 & 1.65 \\
\hline 3. Diagnosis (Dx) with LOS & 1.14 & 1.47 & 2.11 \\
\hline 4. Frequency of Diagnosis (Dx) with LOS & 1.64 & 1.68 & 2.32 \\
\hline 5. Dx with Discharge Date and Time & 0.83 & 0.77 & 1.02 \\
\hline 6. Dx with Unit Transfer Occurrence & 1.15 & 1.22 & 1.67 \\
\hline $\begin{array}{l}\text { 7. Dx with Location of Building, Unit, Room, } \\
\text { and Bed and Discharge Disposition }\end{array}$ & 1.16 & 0.84 & 0.98 \\
\hline 8. Dx with Encounter Type \& LOS & 0.69 & 0.68 & 0.98 \\
\hline 9. Dx with Medical Services \& LOS & 0.44 & 0.38 & 1.02 \\
\hline 10. Provider Service with Dx & 1.35 & 1.44 & 1.92 \\
\hline 11. Highest LOS for MRNs with Admit_Date & 1.45 & 1.46 & 1.62 \\
\hline $\begin{array}{l}\text { 12. Frequency (or number) of Admit_Category } \\
\text { with Discharge_Date }\end{array}$ & 1.86 & 1.76 & 1.89 \\
\hline $\begin{array}{l}\text { 13. Admitted by Ambulance, Interventions, and } \\
\text { Medical Services with Dx }\end{array}$ & 1.79 & 1.87 & 1.89 \\
\hline $\begin{array}{l}\text { 14. Intervention and Location with Admit_Date } \\
\text { and Admit_Time }\end{array}$ & 1.64 & 1.75 & 1.87 \\
\hline $\begin{array}{l}\text { 15. Medical Services with Unit Transfer } \\
\text { Occurrences }\end{array}$ & 1.83 & 1.75 & 1.92 \\
\hline $\begin{array}{l}\text { 16. Admit Category and Discharge with } \\
\text { Transfer }\end{array}$ & 1.64 & 1.75 & 1.75 \\
\hline $\begin{array}{l}\text { 17. Encounter Types with Discharge and } \\
\text { Transfer }\end{array}$ & 1.85 & 1.76 & 1.53 \\
\hline 18. Medical Services with Days in Unit & 1.82 & 1.90 & 2.34 \\
\hline $\begin{array}{l}\text { 19. Admission, Transfer with Intervention and } \\
\text { Encounter }\end{array}$ & 1.97 & 1.88 & 3.02 \\
\hline $\begin{array}{l}\text { 20. Frequency (or number) of Admit_Category } \\
\text { with Patient Services }\end{array}$ & 1.85 & 1.79 & 2.61 \\
\hline 21. Provider Occurrence with Nurse Services & 1.62 & 1.65 & 1.70 \\
\hline 22. Provider with Dx and Intervention & 1.85 & 1.75 & 1.71 \\
\hline
\end{tabular}

For performance benchmarking, three metric measures were used: HDFS ingestion(s), bulk loads to HBase, and query times via Phoenix. We computed the ingestion efficiency $(I E)$ and query efficiency $(Q E)$ of one billion compared to 50 million records using the formula in equation (1):

$I E, Q E=\frac{1 B \times T_{i}(50 M)}{50 M \times T_{i}(1 B)}$ 
Where $T_{i}(N)$ is the time it takes to ingest $N$ records to either HDFS or HBase.

Figure 5 shows the fluxes of the $I E$ for all 60 iterations to three billion. Furthermore, $Q E$ performance of Apache Spark and Apache Drill on the exact same data (Figure 6).

Figure 5. Sixty Iterations of HFile to Bulk loading via MapReduce to HBase Distributed Database. Solid Line is Actual Minutes to Complete All Job Tasks and the Dotted Line is Average Duration

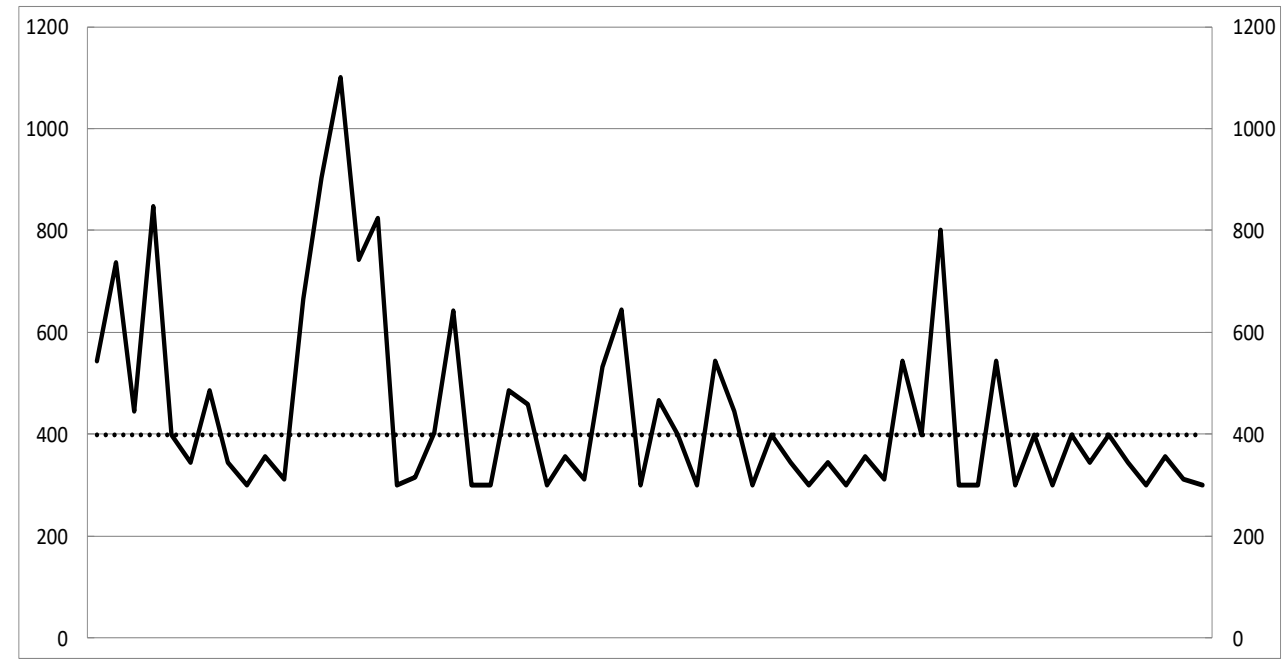

Figure 6. Drill and Spark Query Performance

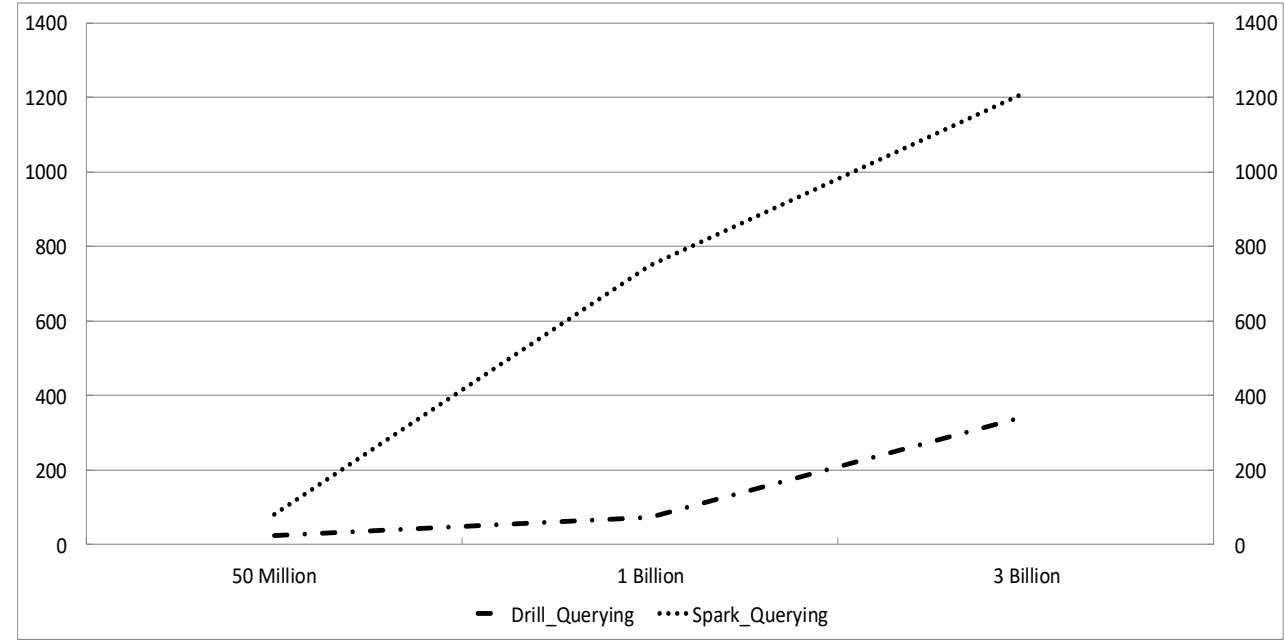

\section{Discussion}

The Big Data Analytics (BDA) platform with Hadoop/MapReduce framework over HBase was successfully implemented. The primary objective of establishing proof-of-concept of interactive platform with high performance was achieved. Further evaluation of the process of how to configure to efficiently 
operate and analyze patient data over a distributed computing system in operational hospital system was accomplished. Nevertheless, there were a few challenges to maintaining the platform operationally: major undertaking to manually run batches of file ingestions to accurately update the database without errors. Furthermore, ongoing update of software versions and integration with Hadoop's ecosystem requires constant maintenance of operating system. Despite having a comprehensive data security/privacy covered by access, authentication and key-store data encryption of HBase, we still faced similar difficulties to obtain real patient data for research. Nonetheless, we used simulated data of real schemas of hospitalization data of VIHA's data warehouse for further change control and development of net new technologies utilizing patient data in non-production environments to test for production.

The bulk of the methodology of the replication of operational generations of the emulated data and queries with Hadoop configurations and other software, i.e., HBase, Spark and Drill, was completed over industrial design and integration of technical Big Data components. Most of the configurations were somewhat out-ofthe-box installations of the distributed filing system and MapReduce components in Java, Python and Scala to perform as expected. Therefore, Hadoop-MapReduce configurations established the platform. It produced the bulk loads of 50 million rows in iteration to one billion were slow. Ingestions to three billion were even slower. It was found that these slow performances were caused by Reducer in placing data to map of database (Mapper was fast $~ 1-6 \mathrm{~min}$ ). Additionally, each iteration of 50 million rows to form key-valued noSQL database took longer because the HBase had to be compacted (and re-indexed) after each batch before running the next iteration. Number of failed ingestions increased, as the file system grew more than expected, and compression of HBase had to run more frequently. If we were to re-run the iteration without running compression, one or all the servers would go "Dead" resulting in system crash and cleanup of the data that was distributed partially in that iteration. At times, a full clean-up was required, so after running HBase for too long, removing error messages required clearing out content on the cluster, re-starting the modules, and even re-loading Hadoop and HBase. Thus, the process of reaching to three billion records via iterations took about a month but these times were as fast as or faster than current data migrations (of a similar size) estimated. Finally, since we did not use real patient data, advanced health patterns or trends were only confirmed to be randomized replicated data clusters.

The most impactful technology of the Big Data components in this study was MapReduce (and Java code performance therein). MapReduce methodology is inherently complex as it has separate Map and Reduce task and steps in its defaulted programming framework, as this study discovered. This study's platform was highly dependent on the efficiency of MapReduce in ingesting files over the six nodes, using this workflow: input $\rightarrow$ map $\rightarrow$ copy/sort $\rightarrow$ reduce $\rightarrow$ output similar to a study by Chenet al. (2012a). Once configurations in Yarn, ZooKeeper and others, the Reducer were optimized with iterations of 50 million rows with data, integrity of the desired clinical event model was established via SQL-like in Apache Phoenix. According to blogs with technical resolutions, enabling or 
disabling services or $x m l$ settings over the platform as expected to be carried because the system relied heavily on InfiniBand (IB) bandwidth. Also there are known issue with using MapReduce over HBase with slow performance after additional indexing of data and its store (Greeshma and Preadeepini, 2016; Maier, 2013; Sakr and Elgammal, 2016; Taylor, 2010; Yu et al., 2016).

The data used in this study consisted of diagnosis codes, personal health numbers, medical record numbers, dates of birth, and location mnemonics (to mention only a few of the 90 columns), as these codes are standardized for hospital systems and, compared to genetic data, easier to replicate in metadata in large volumes. The use of groups of events allows the definition of a phenotype to go beyond diagnosis as coded using the International Classification of Disease, version 9, codes (ICD-9) and potentially allows assessment of the accuracy of assigned codes (Freire et al., 2016; Hripcsak and Albers, 2013). In healthcare, the complexity of Big Data storage and querying increase with unstructured sets of data and/or images. Images take up lots of storage capacity and are difficult to process and next to impossible to query in large volumes. The growth in the volume of medical images produced on a daily basis in modern hospitals has forced a move away from traditional medical image analysis and indexing approaches towards scalable solutions (Wang et al., 2011). MapReduce has been used to speed up and make possible three large-scale medical image processing use-cases: (1) parameter optimization for lung texture classification using support vector machines (SVM), (2) content-based medical image indexing/ retrieval, and (3) dimensional directional wavelet analysis for solid texture classification (Markonis et al., 2012). In their study, as in our study, a default cluster of heterogeneous computing nodes was set up using the Hadoop platform, allowing for a maximum of 42 concurrent Map tasks. The present study did not test the amount and efficiency of concurrent Map tasks of MapReduce to process the data to HBase ingestions; this is something to be investigated further as using real hospital data that is highly unstructured and rich in images might require this enhancement. Moreover, this study ran up against limitations in the ability of the Reducer component of MapReduce more than Map tasks to form the bulk loads of HBase and its NoSQL schema, and, therefore, the Reducer improvements should be investigated before Map tasks.

The complex nature of HBase means that it is difficult to test the robustness of the data in emulations based on real data. Several steps were required to prepare the DAD database alone for statistical rendering before it was sent to CIHI. The actual columns used in this study are the ones used by VIHA to derive the information accurately in a relational database, which ensures the data is in alias pools and not duplicated for any of the encounters. The DAD data also makes calculations (which in the reporting workflow adds columns), which is what the reporting and data warehouse teams also do to form their databases. Adding columns to a NoSQL database is much easier than adding columns to a SQL relational database, and von der Weth and Datta (2012) showed good performance of multi-term keyword searches. Therefore, it is an advantage to have a large database with row keys and column families already set up; this is supported by $\mathrm{Xu}$ et al. (2016), as their middleware ZQL could easily convert relational to non- 
relational data. However, the indexing of HBase proved to decrease the time to ingest the data accurately (so that queries produced accurate information). If the indexing was not reiterated, with the addition of new columns or rows, then the data cannot be queried at all. Spark and Drill performed well with the larger volumes, thus offering an alternative to HBase (without the indexing); however, the data cannot be fully represented without indexing if real patient data is to be used. Not all columns are known, but mimicking an index with family columns does enable simulation of the data model of the hospital. This is a significant drawback, and more data modeling of the relational to the non-relational database is required.

Essentially this study is proposing a row-column key-value (KV) model to the data distributed over a customized BDA platform for healthcare application. Wang et al. (2013) support this study's claim in their statement that non-relational data models, such as the KV model implemented in NoSQL databases. Wang et al. (2014) further stated that NoSQL provided high performance solutions for healthcare, being better suited for high-dimensional data storage and querying, optimized for database scalability and performance. A KV pair data model supports faster queries of large-scale microarray data and can be implemented using HBase (an implementation of Google's BigTable storage system). The new $\mathrm{KV}$ data model implemented on HBase exhibited an average 5.24-fold increase in high-dimensional biological data query performance compared to the relational model implemented on MySQL Cluster and an average 6.47-fold increase on query performance on MongoDB (Sakr and Elgmmal, 2016). Their performance evaluation found that the new KV data model, in particular its implementation in HBase, outperforms the relational model currently implemented; therefore, it supports this study's proposed NoSQL technology for large-scale data management over operational BDA platform.

Nelson and Staggers (2014) have stressed the importance of patient data modeling with Big Data platforms in healthcare. They indicated that a lack of BDA ecosystems is one of the reasons why healthcare is behind other sectors in utilizing current technologies to harness Big Data, and that that nursing informatics and data from nurse progress notes are underutilized in hospital systems. Wang et al. (2014) also compare bioinformatics with healthcare and Big Data applications. Bioinformatics can match extremely large libraries of genetic data to libraries of medications or treatments; however, such matching in real-time over large hospital systems of patient-centric frameworks in Canada is difficult due to current traditional data warehousing practices of storing relational data. Chawla and Davis (2013) and Kuo et al. (2011) argue that even structured data lack interoperability among hospital systems, so that no solutions could possibly link all data. At VIHA, for example, it is difficult to link the DAD and ADT data on encounters, because the DAD data on diagnosis and intervention are not stored together or integrated or have relational dependencies in an all in one data warehouse, while the ADT automatically links the data to encounters. Therefore, more validation is required to match corresponding medical services in ADT to patient diagnosis from the DAD. 
Srirama et al. (2012) indicated that Hadoop is suitable for simple iterative algorithms where they can be expressed as a sequential execution of constant MapReduce models (that could also be configured to be representative of the clinical event model of hospital systems). It is not well suited for complex statistical analysis or iterative problems. To amend the Hadoop's ecosystem weaknesses, we plan to engineer "R" to work over Hadoop (e.g. RHadoop). R and Hadoop complement each other very well in BDA and in data visualizations (Das et al., 2010).

\section{Conclusions}

In this study, Hadoop/MapReduce framework was proposed to implement a data-volume-intensive distributed computing platform. Few studies have tested Big Data tools in Hadoop's ecosystem in healthcare. And even fewer studies have established a simulation of three billion patient records. Therefore, this study achieved the top three V's that define Big Data: high performance (or velocity) over its generator of detailed data (or variety) that formed extremely large quantities (or volume). Our future work will involve user acceptance testing under different simulations and clinical event models.

\section{References}

Canada Health Infoway, 2013.Big Data Analytics in Health - White Paper.

Chawla, N.V. and Davis, D.A. 2013.Bringing Big Data to Personalized Healthcare: A Patient-Centered Framework. J Gen Intern Med 28(Suppl 3), S660-5.

Chen, Y., Alspaugh, S. and Katz, R. 2012a. Interactive Analytical Processing in Big Data Systems: A Cross-Industry Study of MapReduce Workloads, Proceedings of the VLDB Endowment 5 (12), 1802-1813.

Chen, J., Chen, Y., Du, X., Li, C., Lu, J., Zhao, S. and Zhao, X. 2012b. Big data challenge: a data management perspective. Frontiers of Computer Science, 7(2), 157-164.

Chrimes, D., Kuo, M.-H., Moa, B. and Hu, W. 2017a.Towards a Real-time Big Data Analytics Platform for Health Applications.International Journal of Big Data Intelligence, Vol. 4, No. 2.

Chrimes, D., Moa, B., Kuo, M.-H.and Kushniruk, A. 2017b.Operational Efficiencies and Simulated Performance of Big Data Analytics Platform over Billions of Patient Records of a Hospital System.Advances in Science, Technology and Engineering Systems Journal Vol. 2, No. 1, 23-41.

Chunara, R. et al. 2012. Social and news media enable estimation of epidemiological patterns early in the 2010 Haitian cholera outbreak, Am J Trop Med Hyg 86:1, 39-45.

Baro, E., Degoul, S., Beuscart, R. and Chazard, E. 2015.Toward a literature-drive definition of big data in healthcare. BioMed Research International. Volume 2015, Article ID 639021, 9 pages. DOI=http://dx.doi.org/10.1155/2015/639 021.

Dai, L., Gao, X., Guo, Y., Xiao, J. and Zhang, Z. 2012. Bioinformatics clouds for big data manipulation. Biology Direct, 7(43), 1-7.

Das, S., Sismanis, Y. and Beyer, K.S. 2010. Ricardo: Integrating $R$ and Hadoop, Proceedings of the 2010 ACM SIGMOD/PODS Conference (SIGMOD'10). 987-998. 
Deepthi, K. and Anuradha, K. 2016. Big data Mining Using Very-Large-Scale Data Processing Platforms, International journal of engineering research and applications, 6:2, 39-45.

Dufresne, Y., Jeram, S. and Pelletier, A. 2014.The True North Strong and Free Healthcare? Nationalism and Attitudes Towards Private Healthcare Options in Canada. Canadian Journal of Political Science, 47:3, 569-595.

Dugas, A.F. et al. 2012. Google Flu Trends: correlation with emergency department influenza rates and crowding metrics. Clinical infectious diseases 54:4, 463-469.

Dunning, T., Friedman, E., Shiran, T. and Nadeau, J. 2016. Apache-Drill.O'Reilly Media Publications.San Francisco, CA. 2016.

Freire, S.M., Teodoro, D., Wei-Kleiner, F., Sundsvall, E., Karlsson, D. and Lambrix, P. 2016. Comparing the Performance of NoSQL Approaches for Managing ArchetypeBased Electronic Health Record Data. PLoS ONE 11(3), e0150069. DOI=http://10. 1371/journal.pone.0150069.

Greeshma, A.L. and Pradeepini, G. 2016. Input split frequent pattern tree using MapReduce paradigm in Hadoop. Journal of Theoretical and Applied Information Technology, Vol 84 No.2, 260-271.

Grover, M., Malaska, T., Seidman, J. and Shapira, G. 2015.Hadoop Application Architectures: Designing Real-World Big Data Applications. O'Reilly Publishing. San Francisco, California. ISBN 978-1491900086.

Hansen, M.M., Miron-Shatz, T. Lau, A.Y. S. and Paton, C. 2014. Big Data in Science and Healthcare: A Review of Recent Literature and Perspectives, Yearbook of Medical Informatics 9:1, 21-26.

Hripcsak, G. and Albers, D.J. 2013. Next-generation phenotyping of electronic health records.J Am Med Inform Assoc, 20(1),117-21.

Jurney, R. 2013. Agile data science: building data analytics applications with Hadoop. O’Reilly Publications. San Francisco, California.

Kuo, M.H., Kushniruk, A., and Borycki, E. 2011. A Comparison of National Health Data Interoperability Approaches in Taiwan, Denmark and Canada. Electronic Healthcare, 10(2), 14-25.

Kuo, M.-H., Sahama, T., Kushniruk, A.W., Borycki, E.M., and Grunwell, D. 2014. Health Big Data Analytics: Current Perspectives, Challenges and Potential Solutions, International Journal of Big Data Intelligence, 1:4, 114-126.

Lai, W.K., Chen, Y-C., Wu, T-Y., and Obaidat, M.S. 2014. Towards a framework for large-scale multimedia data storage and processing on Hadoop platform. $J$ Supercomput 68, 488-507.

Lith, A. and Mattson, J. 2010. Investigating storage solutions for large data: a comparison of well performing and scalable data storage solutions for real time extraction and batch insertion of data. Master of Science Thesis, Department of Computer Science and Engineering, Chalmers University of Technology, Göteborg, Sweden.

Maier, M. 2013. Towards a Big Data Reference Architecture. Master's Thesis. Eindhoven University of Technology, Department of Mathematics and Computer Science.

Manyika, J., Chui, M., Bughin, J., Brown, B., Dobbs, R., C. Roxburgh, C. and Hung, B. 2014. Big data: The next frontier for innovation, competition, and productivity. URL: https://bit.ly/2gqAa7q.[Accessed 2016-11-26].

Markonis, D., Schaer, R., Eggel, I., Müller, H. and Depeursinge, A. 2012. Using MapReduce for large-scale medical image analysis, Healthcare Informatics, Imaging and Systems Biology (HISB), IEEE Second International Conf. La Jolla, CA, USA, September 27-28, p. 1-10.

Marozzo, F., Talia, D. and Trunfio, P. 2012. P2P-MapReduce: Parallel data processing in dynamic Cloud environments. Journal of Computer and System Sciences, 78(5), 
1382-1402.

Martin-Sanchez, F, and Verspoor, K. 2014. Big Data in Medicine Is Driving Big Changes. Yearbook of Medical Informatics, 9(1), 14-20.

Miller, N.A., Farrow, E.G., Gibson, M., Willig, L.K., Twist, G..., 2015. A 26-hour system of highly sensitive whole genome sequencing for emergency management of genetic diseases, Genome Med. Sep 30, 7(1), 100. DOI= http://10.1186/s13 073-015- 0221-8.

Mohammed, E.A., Far, B. H. and Naugler, C. 2014. Applications of the MapReduce programming framework to clinical big data analysis: current landscape and future trends, BioData Mining, 7: 22, 1-23.

Moniruzzaman, A.B.M, and Hossain, S.A. 2013. NoSQL Database: new era of databases for Big Data Analytics - Classification, Characteristics and Comparison. International Journal of Database Theory and Application, 6(4), 1-14.

Nelson, R. and Staggers, N. 2014.Health Informatics: an interprofessional approach. Mosby, an imprint of Elsevier Inc. Saint Louis, Mo.

Pattuk, E., Kantarcioglu, M., Khadilkar, V., Ulusoy, H. and Mehrotra, S. 2013. BigSecret: A secure data management framework for key-value stores. Tech. Rep. [http://www.utdallas.edu/ exp111430/techReport.pdf] [Accessed December 2015].

Raghupathi, W. and Raghupathi, V. 2014.Big data analytics in healthcare: promise and potential, Health Information Science and Systems 2:3, 1-10.

Saunders, C.J., Miller, N.A., Soden, S.E., Dinwiddie, D.L. Noll, A., Alnadi, N.A. et al. 2012. "Rapid Whole-Genome Sequencing for Genetic Disease Diagnosis in Neonatal Intensive Care Units," Sci. Trans. Med. 4(154), 154ra135. DOI=http://doi.org/10. 1126/scitranslmed.3004041.

Schadt E.E., Linderman, M. D., Sorenson, J., Lee, L. and Nolan, G.P. 2010. Computational solutions to large-scale data management and analysis. Nature Reviews 11, 647-657.

Sakr, S. and Elgammal, A. 2016. Towards a comprehensive data analytics framework for smart healthcare services.Big Data Research 4, 44-58.

Sitto, K. and Presser, M. 2015. Field Guide to Hadoop - An Introduction to Hadoop, Its Ecosystem, and Aligned Technologies, O'Reilly Media, San Francisco, CA.

Srirama, S.N., Jakovits, P., and Vainikko, E. 2012. Adapting scientific computing problems to clouds using MapReduce, Future Generation Computer Systems, 28:1, 184-192.

Taylor, R.C. 2010. An overview of the Hadoop/MapReduce/HBase framework and its current applications in bioinformatics.BMC Bioinformatics, 11(Suppl 12), S1.

Twist, G.P., Gaedigk, A., Miller, N.A., Farrow, E.G., Willig, L.K. 2016. "Constellation: a tool for rapid, automated phenotype assignment of a highly polymorphic pharmacogene, CYP2D6, from whole-genome sequences," NPJ Genomic Med. 1, 15007.

Vaidya, D.P. and Deshpande, S.P. 2015. Parallel Data Mining Architecture for Big Data, International journal of electronics, communication and soft computing science and engineering, 208-213.

von der Weth, C. and Datta, A. 2012. Multi-term Keyword Search in NoSQL Systems. IEEE Internet Computing, January/February, 34-43.

Wang, F., Lee, R., Liu, Q., Aji, A., Zhang, X. and Saltz, J. 2011. Hadoop-GIS: A high performance query system for analytical medical imaging with MapReduce. In: Atlanta - USA: Technical Report, Emory University, 1-13.

Wang, S., Pandis, I., Wu, C., and He, S., Johnson, D., Emam, I., Guitton, F. and Guo, Y. 2014. High dimensional biological data retrieval optimization with NoSQL technology. BMC Genomics 15(Suppl 8), S3.

Wang, Y., Goh, W., Wong, L. and Montana G. 2013. Random forests on Hadoop for genome-wide association studies of multivariate neuroimaging phenotypes. $B M C$ Bioinformatics 14(16), 1-15. 
Wang, B., Li, R. and Perrizo, W. 2014.Big Data Analytics in Bioinformatics and Healthcare, Medical Information Science Reference. ISBN-10:1466666110.

White, T. 2015. Hadoop - The Definitive Guide: Storage and analysis at internet scale. O'Reilly Publishing. San Francisco, California.ISBN 978-1-491-90163-2.

Wu, X., Zhu, X., Wu, G. Q. and Ding, W. 2014.Data Mining with Big Data, IEEE Transactions on Knowledge and Data Engineering, 26:1, 97-107.

Xu, J., Shi, M., Chen, C., Zhang, Z., Fu, J. and Liu, C.H. 2016.ZQL: A unified middleware bridging both relational and NoSQL databases.2016 IEEE 14th Intl Conf on Dependable, Autonomic and Secure Computing, 14th Intl Conf on Pervasive Intelligence and Computing, 2nd Intl Conf on Big Data Intelligence and Computing and Cyber Science and Technology Congress, 730-737.

Yu, S. C., Kao, Q.-L.and Lee, C.R. 2016. Performance Optimization of the SSVD Collaborative Filtering Algorithm on MapReduce Architectures.2016 IEEE 14th Intl Conf on Dependable, Autonomic and Secure Computing, 14th Intl Conf on Pervasive Intelligence and Computing, 2nd Intl Conf on Big Data Intelligence and Computing and Cyber Science and Technology Congress, 612-619.

Zhang, Y. P. et al. 2015. i2 MapReduce: Incremental MapReduce for Mining Evolving Big Data, IEEE Transactions on Knowledge and Data Engineering, 27:7, 1906-1919.

ZooKeeper, 2016.ZooKeeper - Apache Software Foundation Project Home Page. [http://Hadoop.apache.org/ZooKeeper/]. 